\title{
In hospital physiotherapy treatment for Covid-19 patients - Management and clinical practice
}

Received: 04 April, 2020

Accepted: 12 May, 2020

Published: 13 May, 2020

*Corresponding author: Aliza Zeidman, Internal Medicine B, Corona B Department, Hasharon Hospital, Rabin Medical Center, Petah Tikva, Sackler School of Medicine, Tel Aviv University, KKL 7 St Petah Tikva, Israel, Tel: 9723972363; E-mail: alizaz@clalit.org.il

Keywords: COVID-19; Physiotherapy; Telemedicine https://www.peertechz.com

\section{Check for updates}

\section{Rachel Yamin', Jlal Bathish'2, Yael Berman', Anas Isa', Zinaida Fradin ${ }^{2}$ and Aliza Zeidman²*}

'The Department of Physiotherapy, Hasharon Hospital, Israel

${ }^{2}$ Internal Medicine B, Corona B Department, Hasharon Hospital, Rabin Medical Center, Petah Tikva,

Sackler School of Medicine, Tel Aviv University, Israel

\begin{abstract}
World Health Organization has declared corona virus disease (COVID 19) a global pandemic and public health emergency, following the outbreak in Wuhan, China in December 2019. Fever, dry cough and fatigue are the main manifestations, but the main concern is cases that deteriorated to severe pneumonia and ARDS.

The outbreak of COVID- 19 in Israel, in March 2020 caused major changes in the routine work in hospitals. Hasharon hospital, a small community hospital in Petah Tikvah was converted to corona patients admissions only. In accordance with this new reality the physiotherapy service prepared itself to provide treatments tailored to the clinical needs of the Covid 19 patients and the quarantine conditions of these patients hospitalization.
\end{abstract}

During a period of 2 month, we built a unique protocol adjusted to isolated patients and staff, including telemedicine and hands on treatment

Regarding the WHO declaration [1], Department of medicine B was converted to Corona B department. Part of preparing the medical staff and nurses for the new situation we also started preparing premedical staff including physiotherapy, social workers and dieticians to the new endemic situation.

In the pre CORONA era, physiotherapy was a routine part of respiratory patients in Department of internal medicine B. This includes respiratory physiotherapy, general and specific mobilization, functional assessment, prevention of general deconditioning and recommendations for rehabilitation after discharge in various frameworks. There was optimal communication and full cooperation between the physiotherapists and the medical and nursing staff. Based on the good experience we decided to continue with the combined, medical, nursing and physiotherapy treatment in order to improve patient's wellbeing and maybe prevent respiratory deterioration.

Preparation of the physiotherapy staff for the transition to a "corona" hospital includes:

1. The department for prevention of infection transmission trained the staff in the methods of prevention of infection transmission and the donning and removing of protective gear.

2. Regular staff meeting were held dedicated to literary reviews, sharing of new information and insights and instruction on various topics.

3. Structured work procedures were drawn up dealing with the physiotherapy department and for the physiotherapists working in the wards themselves. 
4. Clinical guidelines were drawn up for treating patients via telemedicine and hands on techniques in cooperation with the medical heads of departments.

5. Written exercise sheets and instructional short videos were prepared in different languages which constitute another therapeutic tool

6. Characterization of risk factors, typical preexisting conditions laboratory and imaging results that can affect the physiotherapy treatments including albumin levels, inflammation markers, blood gases and previous functional status.

7. Three objective indexes were chosen to measure improvement in the patient's condition - the Borg scale, saturation and the modified river mead mobility index (MRMI)

Based on the clinical data in the patients file and on our knowledge of respiratory therapy we built a plan for clinical intervention according to the severity of the disease - mild, moderate, severe and critical. These criteria are based on the medical classification, the pathophysiology of the disease and clinical presentation and symptoms of the patient themselves.

Typical symptoms of covid 19 patients which can influence physiotherapy treatment [2]

1) Dyspnea.

2) Dry persistent cough.

3) Obstructive breathing pattern (especially in patients with preexisting lung diseases such as copd or asthma).

4) In some severe cases patients suffer from a buildup of viscous secretion in the lower respiratory tract which are very difficult to clear independently.

5) Atelectasis or loss of lung volume which causes a decrease in ventilation and perfusion.

6) General weakness and higher risk of falls during hospitalization.

7) General functional deterioration.

8) Lack of well-being, social isolation, emotional stress. Patients move around less and do not engage in physical activity.

\section{Two programs of physiotherapy treatment were set up:}

- Telemedicine [3,4]: this facility is now easily available by video communication: any computer or television screen in the patients ward. This screen is pre connected by Wi Fi or digital connection to a screen in the physiotherapist or Doctors office. These big screens enable an accurate picture for both the patient and the therapist. Another form of personal telemedicine can be performed by cellular phone via video chats.
- Hands on treatment carries out in the corona ward itself- A physiotherapist is fully dressed with personal protective suite including N95 mask, gloves and special gown for entering the corona ward and treating the complicated patients and patients on respirators

After reviewing the literature [5-7] and discussing the issue with a multi-disciplinary team in regard to the risk of exposing the physiotherapist when entering the corona ward to the virus verses the benefits of hands on therapy it was decided that in the first stage treatment would be administered via telemedicine. The decision to enter the corona ward will be reached jointly with the medical and multidisciplinary team and the department for prevention of infection transmission.

\section{Criteria for treatment via telemedicine}

1. patient with mild to moderate respiratory symptoms

2. patients able to clear airway secretions independently

3. patients with compliance for telemedicine

\section{Indications for treatment via telemedicine for covid 19 patients}

1. Assistance in clearing airway secretions.

2. Increasing lung volume.

3. Improving breathing pattern and instruction for breathing relaxation techniques.

4. Instruction for independent exercises - active cycle of breathing technique, triflow use, lung drainage positioning.

5. Instruction for positioning - side lying, prone lying, instruction for mobility.

The respiratory physiotherapy treatment will include instruction for function and mobility in order to prevent general deconditioning and falls and if necessary the recommendation for a mobility aid.

\section{Implementation of physiotherapy via telemedicine}

Up until now in the "corona B " ward 40 patients have been treated a total of 90 times via telemedicine.

1. A learning process was necessary to familiarize the staff with the technological and logistical aspects of the telemedicine system.

2. The patients receive instruction for practicing breathing exercises and function in the ward while avoiding fatigue and dyspnea.

3. During the treatment the physiotherapist pays close attention to the patient's saturation and to signs of dyspnea, cough and sputum.

4. A functional assessment is carried out and the patient is instructed regarding mobility accordingly. 
5. There is emphasis on the interpersonal relationship between the physiotherapist and patient and relaxation and stress relieving exercises are integrated in the treatment. In addition due to the quarantine conditions and the feeling of isolation the patient's personal problems should receive extra attention since they can directly influence the patient's clinical condition and their cooperation with the treatment.

6. The patients received written respiratory and general movement exercise sheets and instructional short videos in the language they speak to help recall and practice independently the exercises given to them during the telemedicine session. Follow up was done the next day - the patients were asked if they had practiced independently after the session using the sheets and videos.

\section{Criteria for individual «hands on» treatments}

A patient with clinical evidence of airway secretions which they cannot clear independently. The patient should be alert and able to cooperate with the physiotherapist.

The treatment will include respiratory physiotherapy to increase lung volume and help clear secretions and active movement techniques.

The decision to enter the corona ward will be reached jointly with the medical and multidisciplinary team and the department for prevention of infection transmission.

\section{Indications for hands on treatment for covid 19 patients}

1. Prevention of intubation.

2. Pre extubation - at the stage where the level of sedation is lowered and the level of support provided by the respirator is decreased provided that the patient can cooperate with the physiotherapist. Attention should be also paid to changes in the severity of the respiratory symptoms and inflammation markers.

\section{Post extubation.}

During this period we closely monitored each patient's condition. In some the disease severity increased and they reached the pre intubation stage. During the severe stage of the disease it is important to pay close attention to the inflammation factors and to the chest $\mathrm{x}$ rays and to assess the effectiveness of the treatment in order to avoid overexertion and dyspnea that can cause further overload of the patients respiratory effort and lead to a deterioration in their condition. In certain cases - especially when the patient has a diagnosis of ARDS and is receiving oxygen therapy via a reservoir mask we found that respiratory physiotherapy exacerbated the patient's dyspnea and therefore the treatment was terminated and a report was made to the medical staff.

Over the course of the treatments we observed among many of the patients an improvement in their saturation levels, their
Borg scale score and their functional status. These patients were discharged to their homes or to designated hotels.

We identified the characteristics of patients with a high risk of intubation and played an important part in the treatment they received in order to prevent intubation.

In the corona B ward two patients were intubated and connected to respirators.

One patient collapsed immediately on admittance to the ward and was connected to a respirator and moved to the intensive care unit. This patient has now woken up and is being weaned off the respirator and being treated hands on by a physiotherapist in the ICU.

The other patient was connected to a respirator due to severe dyspnea which developed immediately after the physical exertion of walking to the nursing station.

We are writing case studies about these patients in order to reach practical and therapeutic conclusions which we then share with physiotherapy teams in other hospitals. We presented our conclusions to the physiotherapy community via a webinar on this subject.

We also consider it an important part of our role to maintain close contact with the patient throughout their stay in hospital, to treat them for respiratory complaints, to ensure their function and mobility, to address bio-psych-social issues and to be involved in the decision regarding their discharge to home or to a rehabilitation framework depending on their current and former functional status. When necessary patients are discharged to a rehabilitation center but most patients are discharged to continue rehabilitation in the community. The role of the physiotherapist working in the hospital is to ensure that they communicate with the physiotherapists in the community and the patients themselves to ensure continuance of care.

In our experience we feel that multidisciplinary cooperation - with the doctors, nurses pharmacist, social workers and nutritionist is critical for the success of our treatments. Participation in the daily doctors meetings and communication with other health care workers is highly informative and keeps us up to date on information regarding the corona disease itself and the effectiveness of the treatments been given so we can adjust our treatment programs accordingly.

\section{References}

1. WHO statement on cases of COVID-19 surpassing 100,000. (2020) World Health Organization. Link: https://bit.ly/3dAilOk

2. Huang C, Wang Y, Li X, Ren L, Zhao J, et al. (2020) Clinical features of patients infected with 2019 novel corona virus in Wuhan, China . Lancet 395: 497-506. Link: https://bit.ly/2xTWmCO

3. Sul AR, Lyu DH, Park DA (2018) Effectiveness of tele monitoring versus usual care for chronic obstructive pulmonary disease: A systematic review and meta-analysis. J Telemed Telecare 26: 189-199. Link: https://bit.ly/35PiEIR

4. Gregerson TL, Green A, Frausing E, Ringbæk T2, Brøndum E, et al. (2016) Do tele medicine interventions improve quality of life in patients with COPD? 
A systemic review. Intern J Chron Obstruct Pulmon Dis 11: 809-822. Link: https://bit.ly/3bmqjJn

5. Lennox McNear: Navigating Corona virus disease 2019 (COVID 19) in physiatry: A CAN report for inpatient rehabilitation facilities.
6. Borg GA (1982) Psychophysical bases of perceived exertion. Med Sci Sports Exerc 14: 377-381. Link: https://bit.ly/2xTrDWr

7. Coronavirus Update (2020) CDC updates guidance on discharging patients with COVID 19. American Hospital Association. Link: https://bit.ly/3co4876
Discover a bigger Impact and Visibility of your article publication with

\section{Peertechz Publications}

\section{Highlights}

* Signatory publisher of ORCID

* Signatory Publisher of DORA (San Francisco Declaration on Research Assessment)

- Articles archived in worlds' renowned service providers such as Portico, CNKI, AGRIS, TDNet, Base (Bielefeld University Library), CrossRef, Scilit, J-Gate etc.

* Journals indexed in ICMJE, SHERPA/ROMEO, Google Scholar etc.

* OAI-PMH (Open Archives Initiative Protocol for Metadata Harvesting)

* Dedicated Editorial Board for every journal

* Accurate and rapid peer-review process

* Increased citations of published articles through promotions

* Reduced timeline for article publication

Submit your articles and experience a new surge in publication services (https://www.peertechz.com/submission).

Peertechz journals wishes everlasting success in your every endeavours.

Copyright: ๑ 2020 Yamin R, et al. This is an open-access article distributed under the terms of the Creative Commons Attribution License, which permits unrestricted use distribution, and reproduction in any medium, provided the original author and source are credited.

Citation: Yamin R, Bathish J, Berman Y, Isa A, Zeidman A, et al. (2020) In hospital physiotherapy treatment for Covid-1 9 patients - Management and clinical practice Arch Pulmonol Respir Care 6(1): 017-020. DOI: https://dx.doi.org/10.17352/aprc.000044 